\title{
The Right Versus The Left
}

Politics? No! Well...maybe?

We scientific types have been classified as phylum "analyticum." We are expected to display prominent traits of cold logic and analysis, skepticism, and preciseness of thought and meaning. Put simply in quasi-neurobiopsychological lingo, we are supposed to be "left-brained."

Whether or not you believe in the bimodal distribution of grey matter and personality between hemispheres, there is ample evidence that science would not be where it is today if we had left our right brains behind. Those abstract qualities of intuition, innovation, and creativity are clearly right of center.

But there is more...

Just consider the descriptive talents of those in the visual and literary arts and ask, "Do these talents differ from those displayed in observational science-i.e., in interpreting a metallograph, classifying a specie of plant or animal, recognizing symptoms of an illness, or hypothesizing explanations for experimental results which have outstripped theory?" I vote no!

Many whose principal vocation is science are also skilled in such as art and music. Some have exploited their scientific backgrounds to create new forms and methods for their avocations. This is all good and reassures us that there is not only humanity in science but also that scientists are ambi-brained humans.

Before the advent of sophisticated instruments, our progenitors, the natural philosophers, epitomized the melding of right and left. One could know the stars had individual luminosities and were, in fact, widely separated distant suns, but still appreciate the wonder of the constellations and mythological figures in the sky. If science is less of an art now than it was then, will it be even less so in the future?

We can quantify so many more aspects of observation today and we can do it with continually increasing resolution and precision. Massive supercomputer power can analyze images quantitatively, leaving less need for uniquely human qualitative descriptions. Science deals more now with an unseen microscopic world of quantum phenomena where only the mind's eye can conjure up images for our right sides to appreciate. It may be likely that the right will be called on less for its descriptive talents, but it is hard to envision a substitute for the creative and intuitive attributes.

We contend therefore that we are not in danger of right losing to left, but we are liable to lose the art which has heretofore been a natural companion to the analysis.

Personal litmus tests abound. For example, if the Newton rings in the oil slick on wet pavement bring only optical interference to mind...your right brain has taken the day off. If the Aurora Borealis recalls only cosmic rays, magnetic fields and excited atomic states...your right brain is on hiatus. And, if the color, beauty, charm and flavor of your neighborhood elementary particle have no color, beauty, charm or flavor...only the left is left.

It would, of course, be a shame for the individual practitioner to lose touch with the soft side of science, but there is a greater hazard in such a trend for the set of disciplines as a whole. It could in fact exacerbate an already operative self-limiting algorithm. The patrons of science-i.e., ultimately, the lay public-must be infused with the descriptive excitement of accomplishments and challenges to feel participative and to pay for more good science.

We are not doing as well as we might now to translate and enthuse. If the right side of science becomes still more remote from public awareness because we ourselves dispense with the more qualitative approaches, self-limitation could evolve into self-defeat.

If science is less of an art now...will it be even less so in the future? 